\title{
Establishment and characterization of a cisplatin-resistant cell line, KB-R, derived from oral carcinoma cell line, KB
}

\author{
KENJI NEGORO $^{1 *}$, YUKIO YAMANO ${ }^{2 *}$, KAZUAKI FUSHIMI ${ }^{2}$, KENGO SAITO $^{2}$, KEN NAKATANI $^{1}$, \\ MASASHI SHIIBA ${ }^{2}$, HIDETAKA YOKOE ${ }^{4}$, HIROKI BUKAWA ${ }^{4}$, KATSUHIRO UZAWA ${ }^{2}$, \\ TAKESHI WADA ${ }^{1}$, HIDEKI TANZAWA $^{2,3,4}$ and SHIGEYUKI FUJITA ${ }^{1}$
}

\author{
${ }^{1}$ Department of Oral and Maxillofacial Surgery, School of Medicine, Wakayama Medical University; Departments of \\ ${ }^{2}$ Clinical Molecular Biology and ${ }^{3}$ Center of Excellence (COE) Program in the 21st Century, Graduate School of Medicine, \\ Chiba University; ${ }^{4}$ Division of Oral and Maxillofacial Surgery, Chiba University Hospital, Japan
}

Received January 29, 2007; Accepted March 9, 2007

\begin{abstract}
To investigate the mechanism of the resistance to cisplatin (CDDP), we established the CDDP-resistant cell line, KB-R, from CDDP-sensitive oral carcinoma cell line, KB. The 3-(3, 4-dimethyl-thiazol-2-yl) 2, 5-diphenyltetrazolium bromide (MTT) assay indicated that KB-R is 5.5-fold more resistant to $\mathrm{CDDP}$ than $\mathrm{KB}$. Microarray analysis indicated that the expression levels of 1,718 genes were elevated at least fivefold or more in KB-R, compared with $\mathrm{KB}$. The expression status of ATP binding cassette (ABC) transporter genes, which belong to multi-drug resistance genes, was confirmed by semiquantitative reverse transcriptase-polymerase chain reaction and real-time PCR. MRP1 and $M R P 2$ were up-regulated, whereas $M D R 1$ was down-regulated. Pathway and ontology analysis using the Ingenuity Pathway Analysis tool indicated three highly significant genetic networks including 105 of the 1,718 overexpressed genes and one network including 35 'cell-to-cell signaling and interaction' related genes. Our results suggested that these cell lines, KB and KB-R, may be useful for searching the candidate genes responsible for CDDP-resistance and for further study to understand the mechanism of CDDP-resistance.
\end{abstract}

\section{Introduction}

The development of resistance to anti-tumor drugs appears to be a major impediment to the successful chemotherapy of human carcinoma. Cisplatin or cis-Diamminedichloroplatinum (II) (CDDP) is one of the platinum analogues and the first

Correspondence to: Professor Hideki Tanzawa, Department of Molecular Biology, and Center of Excellence (COE) Program in the 21st Century, Graduate School of Medicine, Chiba University, 1-8-1 Inohana, Chuo-ku, Chiba 260-8670, Japan

E-mail: tanzawap@faculty.chiba-u.jp

${ }^{*}$ Contributed equally

Key words: cisplatin, drug resistance, MTT assay, microarray, pathway analysis choice among anti-tumor agents for the chemotherapy of many malignancies (1-7). The mechanism of cisplatin anticancer activity is believed to be the binding to DNA, interfering in the cell repair mechanism, eventually leading to cell death (7). However, its effectiveness in the treatment of oral SCC is limited because of acquired or intrinsic resistance $(8,9)$. Regardless of the temporal efficacy of CDDP, tumor recurrence often occurs after chemotherapy.

Although the mechanism of resistance to CDDP is still unclear, one of the possible mechanisms is that the alteration in plasma membrane proteins reduces the accumulation of the drug within tumor cells (10). Multidrug resistance (MDR) genes encode cell surface phospho-glycoproteins, responsible for broad-spectrum resistance to chemotherapy, and belong to the ATP-binding cassette (ABC) family, a superfamily of energy-dependent transporter proteins that have ATP-binding sites (11). Up-regulation of MDR genes (MDR1, MRP1, and $M R P 2)$ decreases the intracellular accumulation of CDDP (12-15), and is also believed to increase the intracellular levels of thiol-containing molecules (glutathione and metallothionein), which are necessary for exporting CDDP by an ATP-dependent pump from tumor cells (16), and to enhance DNA repair (17).

For the purpose of understanding the drug resistance well, establishing cultured cell lines resistant to anticancer drugs is primarily necessary. A variety of tissue culture systems have been established to study the biochemical, physiologic, and genetic bases of alterations that result in the development of multidrug resistance. These systems include CDDP-resistant cells, which were derived from KB cells (18).

In the present study, we established the CDDP-resistant $\mathrm{KB}-\mathrm{R}$ cell line from the oral carcinoma $\mathrm{KB}$ cell line, which is sensitive to CDDP, by stepwise dose escalation of CDDP, and investigated the differential gene expression profiles between these CDDP-sensitive and CDDP-resistant cell lines by microarray analysis and real-time quantitative reverse transcriptase-polymerase chain reaction.

\section{Materials and methods}

Cell lines. Human oral carcinoma KB cells were cultured in Dulbecco's modified Eagle's medium (DMEM; Nissui, 
Table I. Primer pairs and amplification conditions for RT-PCR analysis.

\begin{tabular}{|c|c|c|c|c|}
\hline Gene & Primer & Size (bp) & Temperature $\left({ }^{\circ} \mathrm{C}\right)$ & Cycles \\
\hline$M D R 1$ & $\begin{array}{l}\text { (F) 5'-ACCACGATAGCTGAAAACATTCG-3' } \\
\text { (R) 5'-TCAACTGGGCCCCTCTCTCT-3' }\end{array}$ & 153 & 62 & 35 \\
\hline$M R P I$ & $\begin{array}{l}\text { (F) 5'-GGACCTGGACTTCGTTCTCA-3' } \\
\text { (R) 5'-CGCTCCAGATTCCTTCATCCG-3' }\end{array}$ & 302 & 62 & 32 \\
\hline$M R P 2$ & $\begin{array}{l}\text { (F) 5'-CTACTCCATCAATGATAATCTGACC-3' } \\
\text { (R) 5'-CGCTCCAGATTCCTTCATCCG-3' }\end{array}$ & 352 & 62 & 30 \\
\hline GAPDH & $\begin{array}{l}\text { (F) 5'-CATCTCTGCCCCCTCTGCTGA-3' } \\
\text { (R) 5'-GGATGACCTTGCCCACAGCCT-3' }\end{array}$ & 305 & 62 & 25 \\
\hline
\end{tabular}

Tokyo, Japan) supplemented with $10 \%$ fetal bovine serum (FBS; Equitech-Bio, Inc., USA), 100 units/ml penicillin, and $100 \mu \mathrm{g} / \mathrm{ml}$ streptomycin (Gibco BRL, Grand Island, NY) in a highly humidified atmosphere of $5 \% \mathrm{CO}_{2}$ at $37^{\circ} \mathrm{C}$.

According to previously described methods (19), CDDP resistant sub-lines were established by repeated subcultures in the presence of increasing concentrations $(0.1 \mu \mathrm{g} / \mathrm{ml}, 0.2 \mu \mathrm{g} / \mathrm{ml}$, $0.4 \mu \mathrm{g} / \mathrm{ml}$, and $0.5 \mu \mathrm{g} / \mathrm{ml}$ ) of CDDP (kindly provided by Nippon Kayaku Corp. Tokyo, Japan). One of the strongest CDDP-resistant sub-lines was named KB-R, which is fully resistant to CDDP and could grow exponentially in the presence of $0.5 \mu \mathrm{g} / \mathrm{ml} \mathrm{CDDP.} \mathrm{KB-R} \mathrm{showed} \mathrm{no} \mathrm{loss} \mathrm{of} \mathrm{resistance} \mathrm{even}$ after 2-month culture in drug-free medium. Total RNA was obtained from KB cultured without CDDP, whereas it was obtained from KB-R cultured with $0.5 \mu \mathrm{g} / \mathrm{ml}$ of CDDP.

MTT [3-(4,5-dimethyl-thiazol-2-yl)-2,5-diphenyltetrazolium bromide] assay. Proliferation rates were determined by measuring the uptake of tritium thymidine in triplicate by MTT assay (20). Cells $\left(2 \times 10^{3}\right)$ were seeded in each well of a 96-well plate (Falcon; Becton Dickinson Labware, Lincoln Park, NJ, USA) in DMEM containing 10\% FBS. After $24 \mathrm{~h}$, culture medium was exchanged to DMEM with $10 \%$ FBS and several concentrations of CDDP $(0.02,0.04,0.16,0.32,0.62,1.25$, $2.5,5$, and $10 \mu \mathrm{g} / \mathrm{ml})$. After incubation for $24 \mathrm{~h}$, medium was exchanged to CDDP-free DMEM, and the cells were incubated for $72 \mathrm{~h}$. Thereafter, the number of cells was quantified by using an MTT cell growth assay kit (Funakoshi, Tokyo, Japan). Briefly, $10 \mu 1$ of MTT solution was added to each well, and the cells were incubated for a further $4 \mathrm{~h}$. According to the procedure described by Mosmann (21), acid isopropyl alcohol was added to each well as solvent, and then scanning at 550 and $630 \mathrm{~nm}$ was performed with Microplate Reader MTP300 (Corona, Tokyo, Japan). Six wells were used for each drug concentration and the experiment was replicated 3 times. The $50 \%$ inhibitory concentration (IC50) was calculated from the survival curve.

Microarray analysis. Total RNA was isolated from KB cells and KB-R cells by the Trizol method (Invitrogen Corp., Carlsbad, CA, USA) according to the manufacturer's instructions. Double-stranded cDNA was synthesized from $20 \mu \mathrm{g}$ of total RNA using Ready-to-GO You-Prime first-strand beads (Amersham Biosciences, Little Chalfont, Buckinghamshire,
UK) and Oligo(dT) primer (Sigma Genosys, Ishikari, Japan). After phenol/chloroform extraction and ethanol precipitation, a biotin-labeled in vitro transcription reaction was carried out using the cDNA template (Enzo Bioarray, Farmingdale, NY). cRNA (7 $\mu \mathrm{g})$ was fragmented according to Affymetrix protocols and added to the recommended hybridization mixture. Expression profiles were created using the Human Genome U133 Plus 2.0 arrays containing 54,120 probe sets (Affymetrix). Arrays were stained with phycoerythrin-streptavidin, and the signal intensity was amplified by treatment with a biotin-conjugated anti-streptavidin antibody followed by a second staining with phycoerythrin-streptavidin. Arrays stained a second time were scanned using the Affymetrix GeneChip Scanner 3000 (Affymetrix). GeneChip analysis was performed based on the Affymetrix GeneChip Manual (Affymetrix Inc., Santa Clara, CA) with Microarray Analysis Suite (MAS) 5.0, Data Mining Tool (DMT) 2.0, and microarray database software. All of the genes represented on the GeneChip were globally normalized and scaled to a signal intensity of 500. The Microarray Analysis Suite software used the Wilcoxon's test to generate detected (present or absent) calls, and used the calls to statistically determine whether a transcript was expressed or not. After being filtered through a 'present' call $(\mathrm{p}<0.05)$, expression data were analyzed using GeneChip Operating Software 1.1 (Affymetrix) and GeneSpring 6.1 (Silicon Genetics, Redwood City, CA). Fold changes were calculated by comparing transcripts between parents and cisplatin-resistant cell lines.

Analysis of $m R N A$ expression of $A B C$ transporter genes. The expression status of ATP binding cassette $(\mathrm{ABC})$ transporter genes, which belong to multi-drug resistance genes, was confirmed by reverse transcriptase-polymerase chain reaction (RT-PCR) and real-time PCR. cDNA was generated from total RNA extracted from KB and KB-R cells by SuperScript II RT. RT-PCR quantification was used to verify the microarray data. PCR was carried out in a final volume of $10 \mu 1$ that contained 1X LA-PCR buffer (Takara, Shiga, Japan), $2 \mu \mathrm{M}$ of each primer (Table I), $200 \mu \mathrm{M}$ of each dNTP, $1.0 \mu \mathrm{g}$ template cDNA and 0.01 unit of LA-Taq DNA polymerase (Takara). Real-time PCR was performed using a LightCycler FastStart DNA Master SYBR-Green I kit (Roche, Diagnostics GmbH, Mannheim, Germany), according to the procedure provided by the manufacturer. Oligonucleotides used as primers and 
A

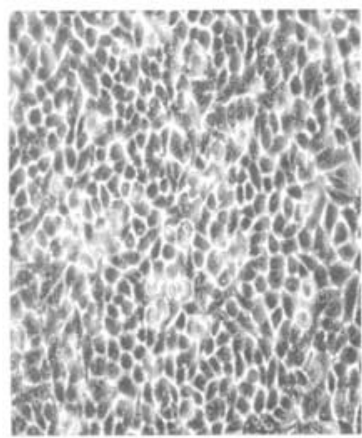

a

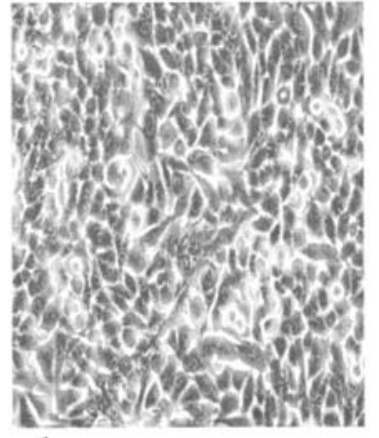

b
B

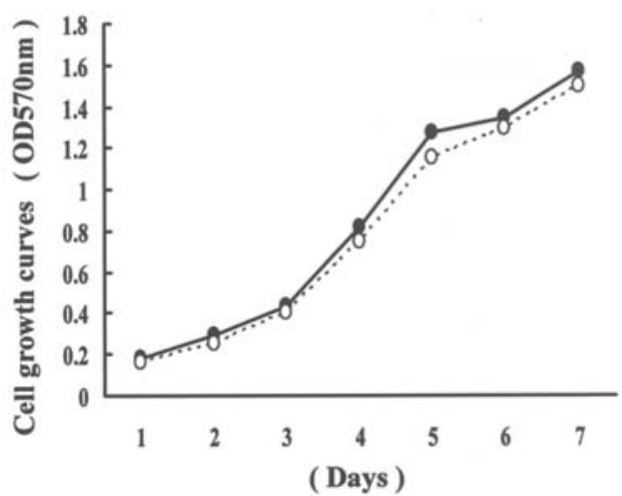

Figure 1. (A) Cell lines. a, Parental oral carcinoma cell line, KB. b, CDDP-resistant cell line, KB-R. There was no morphologic difference between the KB and KB-R cells. (B) Growth curves of both cell lines, KB $(\bullet)$ and KB-R ( $)$. The growth curves of the cell lines also did not differ.

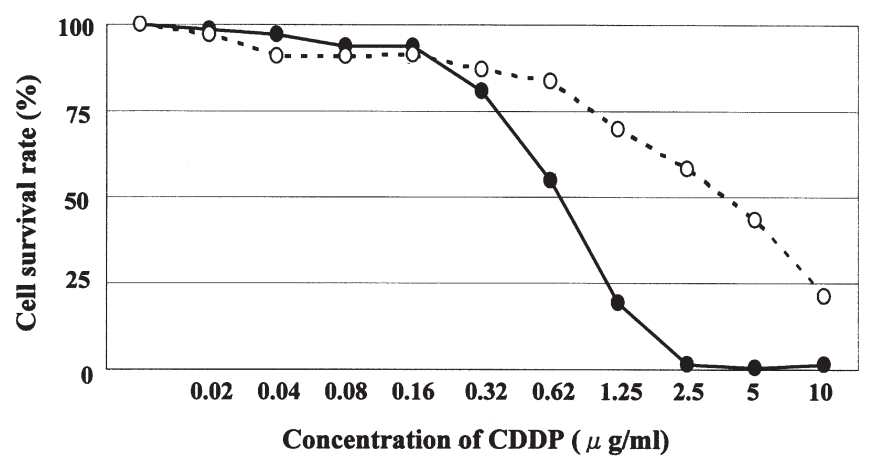

Figure 2. MTT assay. $\mathrm{IC}_{50}$ is the concentration of CDDP that inhibits $50 \%$ of cell proliferation. The $\mathrm{IC}_{50}$ values for the $\mathrm{KB}(\bullet)$ and $\mathrm{KB}-\mathrm{R}(0)$ cells were $0.65 \mu \mathrm{g} / \mathrm{ml}$ and $3.7 \mu \mathrm{g} / \mathrm{ml}$, respectively.

the predicted sizes of amplified PCR products are listed in Table I. Using LightCycler apparatus, we carried out PCR reactions in a final volume of $20 \mu \mathrm{l}$ of a reaction mixture consisting of $2 \mu 1$ of FirstStart DNA Master SYBR-Green I mix, $3 \mathrm{mM} \mathrm{MgCl}_{2}$, and $1 \mu \mathrm{l}$ of the primers according to the manufacturer's instructions. Subsequently, the reaction mixture was loaded into glass capillary tubes and subjected to initial denaturation at $95^{\circ} \mathrm{C}$ for $10 \mathrm{~min}$, followed by 25 to 35 rounds of amplification at $95^{\circ} \mathrm{C}(10 \mathrm{sec})$ for denaturation, $62^{\circ} \mathrm{C}(10 \mathrm{sec})$ for annealing, and $72^{\circ} \mathrm{C}$ for extension, with a temperature slope of $20^{\circ} \mathrm{C} / \mathrm{sec}$, performed in the LightCycler. The transcript amount for the genes differentially expressed in the microarray analysis was estimated from the respective standard curves and normalized to the glyceraldehyde-3-phosphate dehydrogenase (GAPDH) transcript amount determined in corresponding samples.

Network and gene ontology analysis. Under the criteria combining $\mathrm{P}$ calls and fold changes, which suggested that a mean enhancement in expression level by at least five-fold or more in the CDDP-resistant cell line, KB-R, compared to the CDDP-sensitive cell line, $\mathrm{KB}$, in GeneChip analysis by GeneSpring 6.1 data mining software (Silicon Genetics, Redwood City, CA), the significantly altered genes were selected and used for the network generation and pathway analysis. Gene accession numbers and mRNA expression values were imported into the IPA software. The genes were categorized based on molecular functions using the software. The identified genes also were mapped to genetic networks in the IPA database and ranked by score. The score reflects the probability that a collection of genes equal to or greater than the number in a network could be achieved by chance alone. A score of 3 indicates that there is a 1/1,000 chance that the focus genes in a network are there by random chance. Therefore, scores of 3 or higher have a $99.9 \%$ confidence level of not having been generated by random chance alone. This score was used as the cut-off for identifying gene networks. Additionally, gene ontology analysis was performed using the IPA tool.

\section{Results}

Cell growth and MTT assay. The morphology and the growth curves of KB and KB-R cells are shown in Fig. 1 and there is no significant difference between those cells. The sensitivity of $\mathrm{KB}$ and $\mathrm{KB}-\mathrm{R}$ to various concentrations of CDDP was determined by MTT assay and the 50\% inhibitory concentration $\left(\mathrm{IC}_{50}\right)$ values for the $\mathrm{KB}$ and $\mathrm{KB}-\mathrm{R}$ cells were $0.65 \mu \mathrm{g} /$ $\mathrm{ml}$ and $3.7 \mu \mathrm{g} / \mathrm{ml}$, respectively (Fig. 2). The resistance of KB-R to CDDP was 5.5-fold greater than that of $\mathrm{KB}$.

Microarray analysis of $K B$ and $K B-R$ cells. The gene expression profiles of $\mathrm{KB}$ and $\mathrm{KB}-\mathrm{R}$ cells were analyzed using the high-throughput microarray, which contains 54,675 oligonucleotide-based probe sets. The results of microarray analysis showed that the expression levels of 1,718 genes were elevated at least five-fold or more in KB-R, compared with $\mathrm{KB}$.

Evaluation of the expression of $A B C$ transporter genes by $R T-P C R$ and real-time qRT-PCR analysis. We examined $M D R 1, M R P 1$ and $M R P 2$ genes as ABC transporters associated with CDDP-resistance (14-17). According to our microarray data, these $\mathrm{ABC}$ transporters were not indicated to elevate at least five-fold or more in KB-R, compared with KB. The 

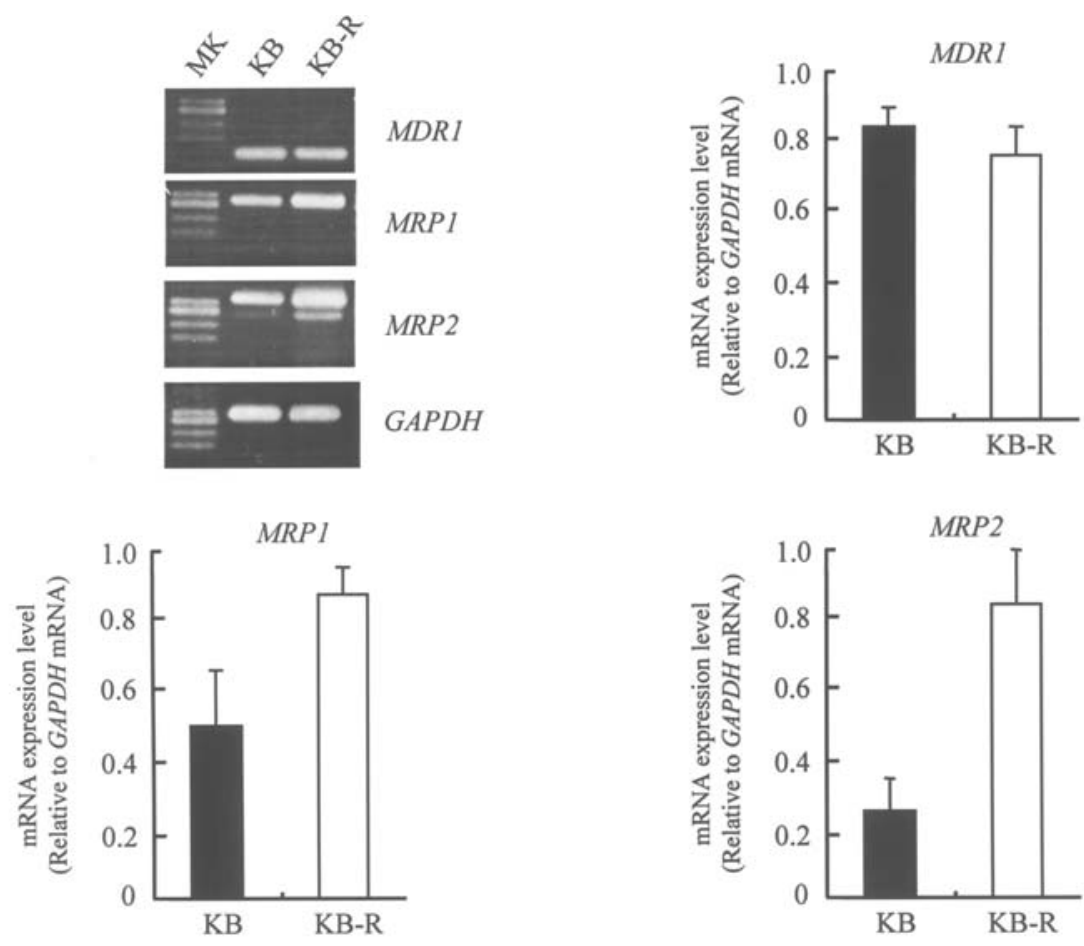

Figure 3. Semi-quantitative RT-PCR and real-time PCR analysis of mRNA expression of ABC transporter genes. (A) RT-PCR. (B) Real-time PCR. GAPDH was amplified as an internal control.

Table II. Three networks formed by overexpressed genes in KB-R cells.

Genetic components in ingenuity networks

Functions

Score $^{\mathrm{a}}$

ABCG2, AKT2, CAMK4, CITED1, CITED4, CREBBP, DACH1, ERG, ESR1, ETV1, FABP4, HAS2, KLF13, LIPE, MSX2, NCOA5, NPAS2, POU1F1, POU2F3, RUNX2, SERPINB9, SIX6, SMAD3, SOX5, SOX6, SOX9, TFAP2B, TFAP2C, TLE1, TLE4, UBE2I, VNN1, VSX1, WNT7A, WW

ADAM12, ARHGAP26, BCAR1, CTNND1, DCN, DOCK1, EGFR, FYB, GRIK1, GRIK2, IL12RB2, JAK2, KCNA2, LCP2, NCK2, NRG1, NRP1, NRP2, PIK3R1, PLXNB1, PTK2B, PTPRC, PTPRK, PTPRS, RAB3B, RAPGEF1, RIMS2, SEMA3E, SEMA4D, SH2D3C, SH3PXD2A, SPTBN1, TUB

ANKS1B, APLP1, APP, BACE1, CD36, CPT1B, CTSG, CYP1A1, DUSP16, EPHX1, F2, F8, F11, FPRL1, GLI2, HOXD3, IGF2, IGFBP3, IL8, JAG1, KLF2, KLKB1, MAP2, MAPK1, MEF2C, NCOA2, NEFH, PI3, SERPINB5, SERPINC1, SERPINE2, TF, THBS1

Gene expression

Tissue development

Connective tissue development

Cellular development

Cellular movement, cell morphology

Hematological system development Organismal functions

Cellular movement

${ }^{\mathrm{a}} \mathrm{A}$ score $>3$ was considered significant.

results of the quantitative assessment of expression of these ABC transporters are shown in Fig. 3. The differing expression of $M D R 1, M R P 1$, and $M R P 2$ genes was clearly indicated by RT-PCR and real-time qRT-PCR between KB and KB-R. $M R P 1$ and $M R P 2$ were up-regulated, whereas $M D R 1$ was down-regulated in KB-R, compared with KB.

Network and gene ontology analysis. We carried out genetic network analysis of the 1,718 genes with elevated expression of at least five-fold or more in KB-R in GeneChip results using the IPA tool. Of these, 105 genes formed three significant networks. These networks indicated functional relationships between gene products based on known interactions in the literature. The IPA tool then revealed that these networks were associated with development, movement, and morphology (Table II). Each network was characterized by different functions. They were merged via overlapping genes (Fig. 4). These results were directly correlated with the intensity of the node color (red) which indicated the degree of up-regulation of focus genes in KB-R compared to KB by microarray analysis 


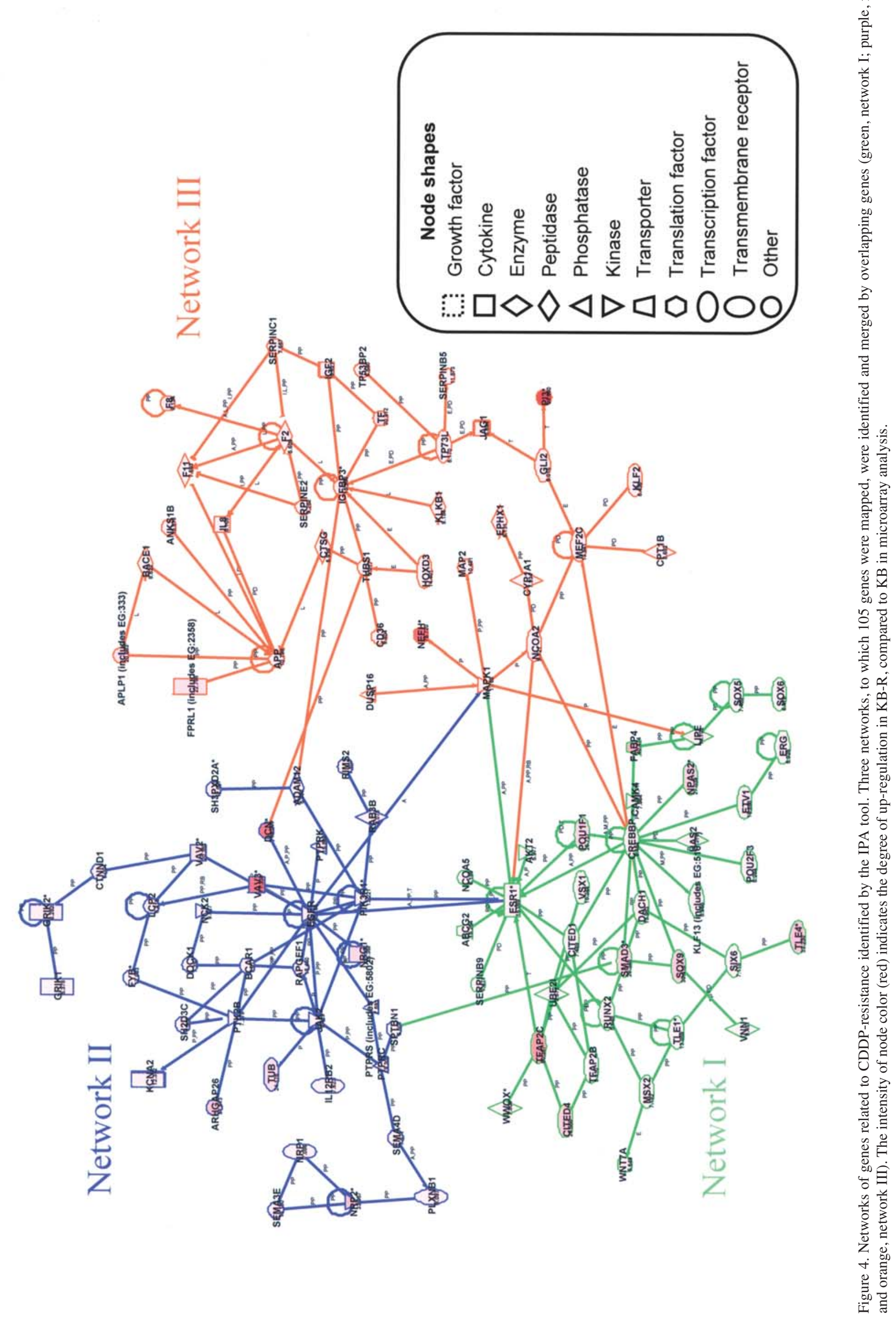


Table III. Gene ontology of identified genes (top 20 of 72 functions detected).

\begin{tabular}{|c|c|c|}
\hline Molecular function & $\mathrm{P}$ value & Gene \\
\hline Cell-to-cell signaling and interaction & $1.67 \mathrm{e}-6$ to $3.53 \mathrm{e}-2$ & 144 \\
\hline Tissue development & $1.67 \mathrm{e}-6$ to $3.46 \mathrm{e}-2$ & 159 \\
\hline Cellular movement & $1.08 \mathrm{e}-5$ to $3.53 \mathrm{e}-2$ & 141 \\
\hline Cellular morphology & $2.84 \mathrm{e}-5$ to $3.13 \mathrm{e}-2$ & 108 \\
\hline Cellular assembly and organization & $2.84 \mathrm{e}-5$ to $3.53 \mathrm{e}-2$ & 87 \\
\hline Nervous system development and function & $3.90 \mathrm{e}-5$ to $3.13 \mathrm{e}-2$ & 124 \\
\hline Cell signaling & $4.50 \mathrm{e}-5$ to $3.46 \mathrm{e}-2$ & 149 \\
\hline Cellular development & $1.09 \mathrm{e}-4$ to $3.53 \mathrm{e}-2$ & 142 \\
\hline Cancer & $1.82 \mathrm{e}-4$ to $3.53 \mathrm{e}-2$ & 104 \\
\hline Skeletal and muscular disorders & $3.24 \mathrm{e}-4$ to $3.53 \mathrm{e}-2$ & 15 \\
\hline Cellular compromise & $3.30 \mathrm{e}-4$ to $3.04 \mathrm{e}-2$ & 30 \\
\hline Neurological disease & $3.30 \mathrm{e}-4$ to $3.53 \mathrm{e}-2$ & 28 \\
\hline Hematological disease & $4.83 \mathrm{e}-4$ to $2.92 \mathrm{e}-2$ & 26 \\
\hline Carbohydrate metabolism & $5.12 \mathrm{e}-4$ to $3.32 \mathrm{e}-2$ & 38 \\
\hline Molecular transport & $5.12 \mathrm{e}-4$ to $3.46 \mathrm{e}-2$ & 81 \\
\hline Skeletal and muscular system development and function & $6.28 \mathrm{e}-4$ to $2.70 \mathrm{e}-2$ & 53 \\
\hline Cellular growth and proliferation & $6.56 \mathrm{e}-4$ to $3.46 \mathrm{e}-2$ & 52 \\
\hline Connective tissue development and function & $6.56 \mathrm{e}-4$ to $3.53 \mathrm{e}-2$ & 32 \\
\hline Organismal development & $6.56 \mathrm{e}-4$ to $3.36 \mathrm{e}-2$ & 37 \\
\hline Small molecule biochemistry & $6.56 \mathrm{e}-4$ to $3.53 \mathrm{e}-2$ & 73 \\
\hline
\end{tabular}

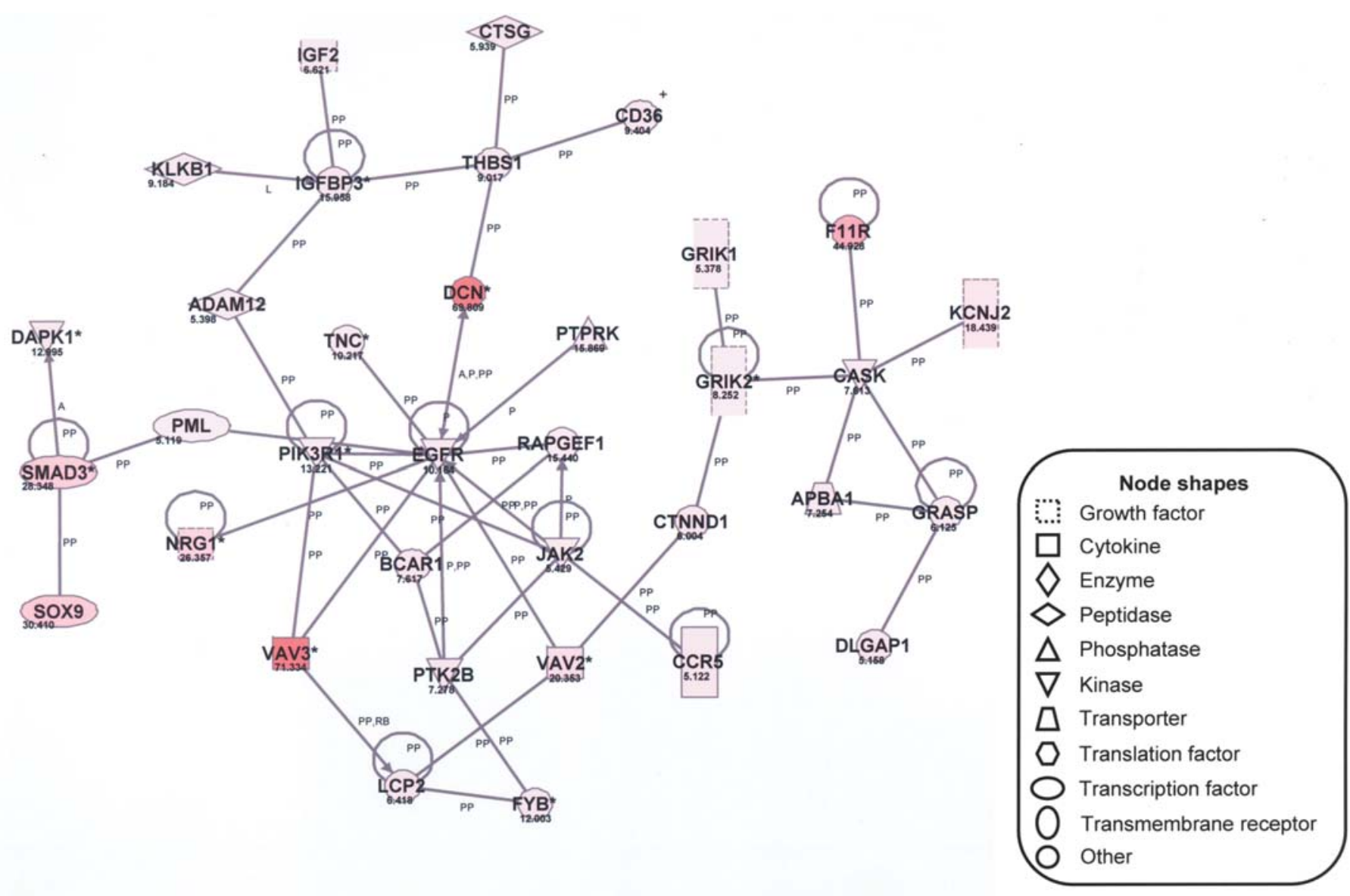

Figure 5. The genetic network related to the top function 'cell-to-cell signaling and interaction' identified by ontology analysis. Out of 144 'cell-to-cell signaling and interaction' related genes, 35 genes were mapped to this network. The intensity of node color (red) indicates the degree of up-regulation in KB-R, compared to $\mathrm{KB}$ in microarray analysis. 
in Fig. 4. Gene ontology analysis also was performed using the IPA tool. A total of 72 functions were identified as high level functions and the top 20 of the 72 functions are tabulated in Table III. 'Cell-to-cell signaling and interaction' function had the highest $\mathrm{P}$ value ( $\mathrm{P}=1.67 \mathrm{e}-6$ to $3.53 \mathrm{e}-2)$. Furthermore, to investigate the network of 144 'cell-to-cell signaling and interaction'-related genes, we performed network analysis. Consequently, we identified one network (Fig. 5) that included 35 'cell-to-cell signaling and interaction'-related genes.

\section{Discussion}

Platinum analogues are key anticancer agents used in the chemotherapy of solid tumors, such as ovary (1), advanced bladder carcinoma (2), testis (3), head and neck carcinoma (4-6), and lung carcinoma (7). Cisplatin (CDDP) is one of the platinum analogues and the mechanism of CDDP anti-cancer activity is believed to be the binding to DNA, interfering in the cell repair mechanism, eventually leading to cell death (7). However, the effectiveness of CDDP in the treatment of cancer is limited because of acquired or intrinsic resistance $(8,9)$. Though several mechanisms of resistance to CDDP have been investigated, there is no mechanism completely to elucidate the clinical response to CDDP-therapy. CDDPresistant cells are indispensable for the investigation of the mechanisms of the CDDP-resistance and several cell lines that are resistant to CDDP have been established $(8,22-26)$.

In the present study, we established CDDP-resistant cell line, KB-R, from parent cell line, KB, which was derived from oral carcinoma. KB-R cells indicated strong resistance to $\mathrm{CDDP}$, compared with KB cells. Although several cell lines have been reported to have 2.5- to 4-fold resistance, KB-R showed 5.5-fold strong resistance to CDDP. MDR1, MRP1 and $M R P 2$ genes are well known as ABC transporters associated with CDDP-resistance (14-17). In KB-R cells, these ABC transporters were not indicated to elevate at least five-fold, compared with KB. Moreover, MDRl was down-regulated in KB-R, though $M R P 1$ and $M R P 2$ were up-regulated. Therefore, the strong CDDP-resistance of KB-R cells is not able to be elucidated only by $\mathrm{ABC}$ transporter gene function. Many other factors are sure to contribute to the CDDP-resistance in KB-R cells.

The use of microarray analysis enables the evaluation of a large number of genes and may identify potential target genes responsible for resistance and response to chemotherapy. The high-throughput microarray identified 1,718 overexpressed genes in KB-R cells. For the purpose of further identification of the candidate genes responsible for CDDP-resistance, functional network analysis and gene ontology analysis were performed using the IPA tool. Table II and Fig. 4 show that 105 genes formed 3 genetic networks involved in gene expression, tissue development, connective tissue development, cellular development, cellular movement, cell morphology, hematological system development and organismal functions. The top 20 of the 72 functions are tabulated in Table III and the top function was 'cell-to-cell signaling and interaction' with the highest $\mathrm{P}$ value $(\mathrm{P}=1.67 \mathrm{e}-6$ to $3.53 \mathrm{e}-2)$. Thirty five of 144 'cell-to-cell signaling and interaction'-related genes formed one network (Fig. 5). This comprehensive gene expression profiling-assisted pathway analysis provided an appealing approach for effectively identifying candidate genes and pathways involved in CDDP-resistance. These genes may contribute to a basic understanding of the molecular mechanisms of CDDP-resistance and further study will be necessary to reveal the mechanism of CDDP-resistance.

\section{References}

1. Reed E, Ozols RF, Tarone R, Yuspa SH and Poirier MC: Platinum-DNA adducts in leukocyte DNA correlate with disease response in ovarian cancer patients receiving platinumbased chemotherapy. Proc Natl Acad Sci USA 84: 5024-5028, 1987.

2. Rosenberg B: Fundamental studies with cisplatin. Cancer 55: 2303-2316, 1985

3. Reed E, Ozols RF, Tarone R, Yuspa SH and Poirier MC: The measurement of cisplatin-DNA adduct levels in testicular cancer patients. Carcinogenesis 9: 1909-1911, 1988.

4. Cognetti F, Pinnaro P, Carlini P, Ruggeri EM, Ambesi Impiombato F, Del Vecchio MR, Giannarelli D and Perrino A: Neoadjuvant chemotherapy in previously untreated patients with advanced head and neck squamous cell cancer. Cancer 62: 251-261, 1988.

5. Decker DA, Drelichman A, Jacobs J, Hoschner J, Kinzie J, Loh JJ, Weaver A and Al-Sarraf M: Adjuvant chemotherapy with cis-diamminodichloroplatinum and 120-hour infusion 5fluorouracil in stage III and IV squamous cell carcinoma of the head and neck. Cancer 51: 1353-1355, 1983.

6. Ervin TJ, Clark JR, Weichselbaum RR, Fallon BG, Miller D, Fabian RL, Posner MR, Norris CM Jr, Tuttle SA and Schoenfeld DA: An analysis of induction and adjuvant chemotherapy in the multidisciplinary treatment of squamous cell carcinoma of the head and neck. J Clin Oncol 5: 10-20, 1987.

7. Makimoto $\mathrm{T}$, Tsuchiya $\mathrm{S}$, Nakano $\mathrm{H}$, Watanabe $\mathrm{S}$, Minato $\mathrm{K}$, Takise A, Ezawa K, Fueki N, Naruse I, Nomoto T, Takei Y, Ishihara S, Mori M and Saitoh R: A phase II study of carboplatin-cisplatin-etoposide combination chemotherapy in advanced non-small-cell lung cancer. Am J Clin Oncol 20: 51-54, 1997.

8. Higuchi E, Oridate N, Furuta Y, Suzuki S, Hatakeyama H, Sawa H, Sunayashiki-Kusuzaki K, Yamazaki K, Inuyama Y and Fukuda S: Differentially expressed genes associated with CIS-diamminedichloroplatinum (II) resistance in head and neck cancer using differential display and cDNA microarray. Head Neck 25: 187-193, 2003.

9. Scotto KW and Bertino JR: Natural and acquired resistance to chemotherapeutic agents. The molecular basis of cancer. 2nd edition. W.B. Sanders Co, pp407-422, 2001.

10. Jin S and Scotto KW: Transcriptional regulation of the MDRI gene by histone acetyltransferase and deacetylase is mediated by NF-Y. Mol Cell Biol 18: 4377-4384, 1998

11. Hinoshita E, Uchiumi T, Taguchi K, Kinukawa N, Tsuneyoshi M, Maehara Y, Sugimachi K and Kuwano M: Increased expression of an ATP-binding cassette superfamily transporter, multidrug resistance protein 2 , in human colorectal carcinomas. Clin Cancer Res 6: 2401-2407, 2000.

12. Perez RP: Cellular and molecular determinants of cisplatin resistance. Eur J Cancer 34: 1535-1542, 1998.

13. Bordow SB, Haber M, Madafiglio J, Cheung B, Marshall GM and Norris MD: Expression of the multidrug resistance-associated protein (MRP) gene correlates with amplification and overexpression of the N-myc oncogene in childhood neuroblastoma. Cancer Res 54: 5036-5040, 1994.

14. Futscher BW, Abbaszadegan MR, Domann F and Dalton WS Analysis of MRP mRNA in mitoxantrone-selected, multidrug resistant human tumor cells. Biochem Pharmacol 47: 1601-1606, 1994.

15. Kamazawa S, Kigawa J, Kanamori Y, Itamochi H, Sato S, Iba T and Terakawa N: Multidrug resistance gene-1 is a useful predictor of Paclitaxel-based chemotherapy for patients with ovarian cancer. Gynecol Oncol 86: 171-176, 2002.

16. Ishikawa $\mathrm{T}$ and Ali-Osman F: Glutathione-associated cisdiamminedichloroplatinum (II) metabolism and ATP-dependent efflux from leukemia cells: molecular characterization of glutathione-platinum complex and its biological siginificance. J Biol Chem 268: 20116-20125, 1993.

17. Kartalou M and Essigmann JM: Mechanism of resistance to cisplatin. Mutat Res 478: 23-43, 2001. 
18. Zhang P, Zhang Z, Zhou X, Qiu W, Chen F and Chen W: Identification of genes associated with cisplatin resistance in human oral squamous cell carcinoma cell line. BMC Cancer 6: 224, 2006.

19. Hong WS, Saijo N, Sasaki Y, Minato K, Nakano H, Nakagawa K, Fujuwara Y and Nomura K: Establishment and characterization of cisplatin-resistant sublines of human lung cancer cell lines. Int J Cancer 41: 462-467, 1988.

20. Carmichael J, DeGraff WG, Gazdar AF, Minna JD and Mitchell JB: Evaluation of a tetrazolium-based semiautomated calorimetric assay: assessment of chemosensitivity testing. Cancer Res 47: 936-942, 1987.

21. Mosmann T: Rapid colorimetric assay for cellular growth and survival: application to proliferation and cytotoxicity assays. Immunol Methods 65: 55-63, 1983.

22. Ariyoshi Y, Shimahara M and Tanigawa N: Study on chemosensitivity of oral squamous cell carcinomas by histoculture drug response assay. Oral Oncol 39: 701-707, 2003.
23. Sawada S, Mese H, Sasaki A, Yoshioka N and Matsumura T: Combination chemotherapy of paclitaxel and cisplatin induces apoptosis with Bcl-2 phosphorylation in a cisplatin-resistant human epidermoid carcinoma cell line. Cancer Chemother Pharmacol 51: 505-511, 2003.

24. Hong WS, Saijo N, Sasaki Y, Minato K, Nakano H, Nakagawa K, Fujiwara Y, Nomura K and Twentyman PR: Establishment and characterization of cisplatin-resistant sublines of human lung cancer cell lines. Int J Cancer 41: 462-467, 1988.

25. Nakatani K, Nakamura M, Uzawa K, Wada T, Seki N, Tanzawa H and Fujita S: Establishment and gene analysis of a cisplatinresistant cell line, Sa-3R, derived from oral squamous cell carcinoma. Oncol Rep 13: 709-714, 2005.

26. Nakamura M, Nakatani K, Uzawa K, Ono K, Uesugi H, Ogawara K, Shiiba M, Bukawa H, Yokoe H, Wada T, Fujita S and Tanzawa H: Establishment and characterization of a cisplatinresistant oral squamous cell carcinoma cell line, H-1R. Oncol Rep 14: 1281-1286, 2005. 